Article

\title{
The Influence of Rehabilitation Techniques on Static and Variabile Loads in Case of a HSLA Steel Samples
}

\author{
BabisClaudiu ${ }^{1}$, Solomon Gheorghe $^{1}$, Iacobescu Gabriel ${ }^{1}$, Chivu Oana ${ }^{1 *}$ and PurcareaAnca \\ Alexandra $^{2}$ \\ 1 Romania, Politehnica University of Bucharest, Faculty of Engineering and Management of Technological \\ Systems;claudiubbs@gmail.com;ghe.solomon@gmail.com;gabiiacobescu@yahoo.com;virlan_oana@yahoo.c \\ o.uk; asemenescu2002@yahoo.com \\ 2 Roamania, Politehnica University of Bucharest, Faculty of Entrepreneurship, Business Engineering and \\ Management; apurcarea@gmail.com \\ * Correspondence: virlan_oana@yahoo.co.uk; Tel.: +40-722-219-498
}

\begin{abstract}
There are many welded structures in the world such as bridges and viaducts that are subject to fatigue. These structures, generally made of non-alloy or low-alloy steels, have been put into operation some of them with many years ago and have accumulated a large number of variable load cycles over the time. For this reason the occurrence of fatigue phenomenon is inevitable and consists in the occurrence of failures at stresses applied to the structure, below the yield limit of the material. These stresses under the static loads would not cause the failures to appear..This paper will investigate whether two reconditioning techniques "weld toe grinding" and "WIG remelting weld toe", influences favorably the behavior of welded structures made from HSLA steel, in static and variable loads and therefore if the application of these techniques is justified in both cases. In the paper will be presented the chemical composition and mechanical properties of the base and filler materials, micro and macrostructures, graphics with the variation of microhardness, static and fatigue tensile tests will be performed, and it will be rised durability curve in case of fatigue tests.
\end{abstract}

Keywords: weld toe grinding; WIG remelting weld toe; fatigue

\section{Introduction}

In the case of welded structures a very large proportion of use is represented by fillet welded joints. Also in the case of bridges welded structures we often meet static loads, as well as variable loads that cause fatigue failures [1-7]. In the case of static loads, things are simpler and clearer in the sense that structural failures occurs when the tear resistance of the base material is exceeded. In the case of variable loads, things are a little more complicated. The fatigue failures in case of the welded bridges and welded structures in general, are causedand can be estimated on the one hand by the stress cycles accumulated over time, by the internal stress concentrators such as the type of macrostructural defects that extend over time (pore, cracks, etc.), but in the greatest extent by the external stress concentrators determined by the convex geometric shape of the welding seams [8-14]. In the past, the convex geometry of the welding seams was believed to provide better mechanical strength. In fact, this geometric shape determines high stress concentrators at the intersection between the welding seam and the base material. The effect of these cumulative stress peaks with the variable loads to which the structures are subjected may have catastrophic effects in 
the present, consisting of serious accidents that may result in loss of life [15]. It is therefore necessary to monitor these structures and their rehabilitation in optimal conditions from a technical and economical point of view. In the case of the fatigue phenomenon, as we can state before, the failure occurs at stresses below the yield strength of the base material, stresses which in the case of static loads would not even produce permanent deformations in the structure and implicitly, no failures. Variable loads are those in which there is a large number of stress cycles wichis varying between a maximum and a minimum value of the stress, which as stated above is below the material yield strength. In the case of these variable loads, even if the applied loads are below the yield strength of the base material, the failure occurs due to the fact that the structure is very sensitive to the stress concentrators, which are also called "local stress peaks". For cruciform fillet welded joints which are the subject of this work, the external stress concentrators are found on the at the intersection between the base and the filler material, areas named "weld toe areas" in the specialty literature and on the other hand at the root of the welding, as shown in figure 1 . These "weld toe areas" in the case of variable loads are very dangerous, and from there, are initiated many cracks that can sometimes have catastrophic effects on the structure [16,17]. In figure 1, we marked with $\mathrm{K}$ the cords of the welding, with $\mathrm{R} / \mathrm{r}$ the radius of the connection between the filler and the base material, $\mathrm{s}$ is the thickness of the plates, $\sigma_{\max }$ is the maximum stress, $\sigma_{\mathrm{n}}$ is the nominal stress and $\mathrm{F}$ is the force the force acting on the weld joint.

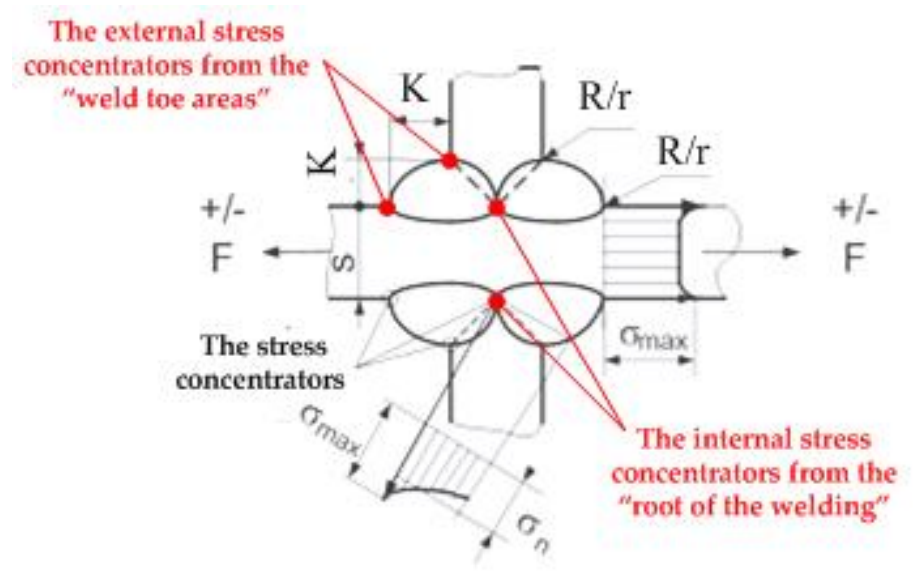

Figure 1 The "weld toe" areas, of the the stress concentration; K-the cord of the welding seam; R/r the radius of the connection between the filler and the base material.

In order to ameliorate the stress peaks in the "welding toe areas" that appear as the cruciform fillet welded joints, as we have already said, we use several rehabilitation techniques [3]. These techniques aim is in fact to increase the connection radius between the base and the filler material, in order to reduce the stress concentration. In this paper we will analyze the effects of the influence of the two rehabilitation techniques: grinding weld toe" rehabilitation technique and "WIG remelting weld toe" rehabilitation technique [18]. The "grinding weld toe" rehabilitation technique consists in the milling of the top of the welding cord, along the intersection line between the filler and the base material, for the joints between pipes (T, Y or K ) and for fillet weld joints between tables. The tools recommended for this process are the wolfram high-speed finger cutters. The "WIG remelting weld toe" rehabilitation technique consists of remeltinging the weld metal to a depth of about $2 \mathrm{~mm}$ across the welding toe, without adding a filler material. 
In the paper are analyzed cruciform fillet welded joints welded with shilded gas welding procedure, using a copper coated carbon steel wire, in single pass, because on the one hand the cruciform fillet welded joints that are very widespread in welded constructions such as bridges and viaducts, presents the highest failure potential due to triaxial stresses, and on the other hand the welding with that copper coated carbon steel wire is a frequent practice for the beneficial effect in case of fatigue life of the welded structure. Also, in the paper is made a comparison between the effect of the two mentioned rehabilitation techniques applied on the cruciform fillet welded joints, both in the case of static and variable loads, in order to draw conclusions about the efficiency of these techniques depending on the type of load [19].

\section{Materials and Methods}

The experiment presented in this paper is extracted from a larger study of five cruciform fillet welded samples marked A, B, C, D and E, which were welded under different conditions and on which we applied those two rehabilitation techniques "welding toe grinding" and "WIG remelting welding toe". The object of the study presented in this paper is only the cruciform fillet welded sample marked with $\mathrm{D}$. The cruciform fillet welded sample marked with $\mathrm{D}$ is made from two vertical plates marked with 1 and an horizontal plate marked with 2, all welded through the shilded gas welding procedure, with full wire and three welded rows in horizontal position. The cruciform fillet welded sample marked with D is shown as shape and dimensions in figure 2.

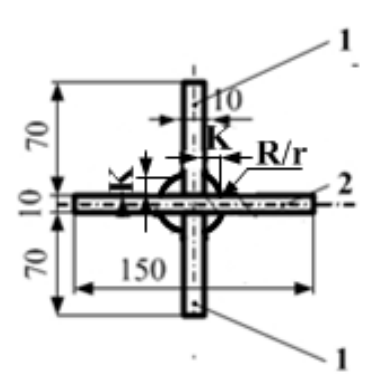

(a)

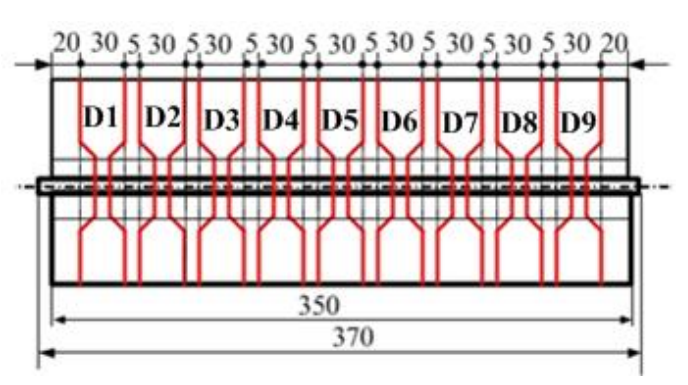

(b)

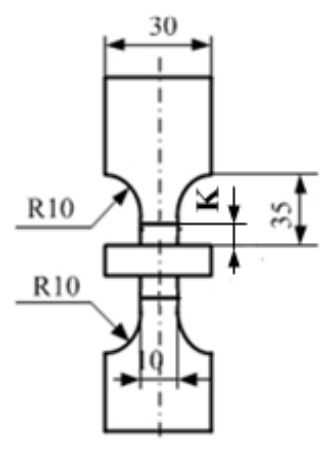

(c)

Figure 2.The shape and size of welding sample D; a- front view sketch welding sample, b-test specimens C1-C9, c-static and fatigue specimen test after milling

The material from which the cruciform fillet welded sample D is made is a high-strength low-alloy steel (HSLA). This material is a type of alloy steel that provides better mechanical properties or greater resistance to corrosion than carbon steel. HSLA steels vary from other steels in that they are not made to meet a specific chemical composition but rather to specific mechanical properties. They have a carbon content between $0.05-0.25 \%$ to retain formability and weldability. Other alloying elements include up to $2.0 \%$ manganese and small quantities of copper, nickel, niobium, nitrogen, vanadium, chromium, molybdenum, titanium, calcium, rare earth elements, or zirconium. Copper, titanium, vanadium, and niobium are added for strengthening purposes. These elements are intended to alter the microstructure of carbon steels, which is usually a ferrite-pearlite aggregate, to produce a very fine dispersion of alloy carbides in an almost pure ferrite matrix. This eliminates the toughness-reducing effect of a pearlitic volume fraction yet maintains and increases the material's strength by refining the grain size, which in the case of ferrite increases yield strength 
by $50 \%$ for every halving of the mean grain diameter. Precipitation strengthening plays a minor role, too. Their yield strengths can be anywhere between 250-590 megapascals (36,000-86,000 psi). Because of their higher strength and toughness HSLA steels usually require 25 to $30 \%$ more power to form, as compared to carbon steels.

Copper, silicon, nickel, chromium, and phosphorus are added to increase corrosion resistance. Zirconium, calcium, and rare earth elements are added for sulfide-inclusion shape control which increases formability. These are needed because most HSLA steels have directionally sensitive properties. Formability and impact strength can vary significantly when tested longitudinally and transversely to the grain. Bends that are parallel to the longitudinal grain are more likely to crack around the outer edge because it experiences tensile loads. This directional characteristic is substantially reduced in HSLA steels that have been treated for sulfide shape control.

HSLA are used in cars, trucks, cranes, bridges, roller coasters and other structures that are designed to handle large amounts of stress or need a good strength-to-weight ratio. HSLA steel cross-sections and structures are usually 20 to $30 \%$ lighter than a carbon steel with the same strength.

HSLA steels are also more resistant to rust than most carbon steels because of their lack of pearlite - the fine layers of ferrite (almost pure iron) and cementite in pearlite. HSLA steels usually have densities of around $7800 \mathrm{~kg} / \mathrm{m}^{3}$.

The chemical composition for the 945 A HSLA steel is presented in table 1.

Table 1. The chemical composition for the 945 A HSLA steel

\begin{tabular}{ccccccc}
\hline Grade & $\begin{array}{c}\text { C-max } \\
(\%)\end{array}$ & $\begin{array}{c}\text { Mn-max } \\
(\%)\end{array}$ & $\begin{array}{c}\text { P-max } \\
(\%)\end{array}$ & $\begin{array}{c}\text { S-max } \\
(\%)\end{array}$ & $\begin{array}{c}\text { Si-max } \\
(\%)\end{array}$ & Notes \\
\hline $945 \mathrm{~A}$ & 0.15 & 1.0 & 0.04 & 0.05 & 0.9 & - \\
\hline
\end{tabular}

The mechanical properties for the the 945 A HSLA steel is presented in table 2.

Table 2. The mechanical properties for the 945 A HSLA steel

\begin{tabular}{cccc}
\hline Grade & Form & $\begin{array}{c}\text { Yield strength-min } \\
(\mathrm{MPa})\end{array}$ & $\begin{array}{c}\text { Ultimate tensile strength-min } \\
(\mathrm{MPa})\end{array}$ \\
\hline 945A & Plates, shapes and bars & 310 & 448 \\
\hline
\end{tabular}

The ranking of some technological properties is presented in table 3.

Table 3. The ranking of some technological propertiesfor the 945 A HSLA steel

\begin{tabular}{cccc}
\hline $\begin{array}{c}\text { Technological } \\
\text { properties }\end{array}$ & Weldability & Formability & Toughness \\
\hline Rank & Best & Best & Best \\
\hline
\end{tabular}

Nine specimens marked with D1-D9 were cut from welding sample D, as we can see in figure 2(b). The specimens marked with D1, D4 and D7 will be used for static traction tests until fracture, and the other specimens marked with D2, D3, D5, DC6, D8 and D9 will be used for fatigue tests. Those two rehabilitation techniques "welding toe grinding" and "WIG remelting welding toe" were applied before static and fatigue tests were carried out, as follows: D2 and D3 are specimens with no rehabilitation techniques applied, D5 and D6 are specimens on which the "grinding weld toe" rehabilitation technique is applied and D8 and D9 are the specimens with the "WIG remeltingwelding toe" rehabilitation technique applied. Both the static and fatigue specimens were obtained by mechanical cutting from the cruciform fillet welded sample D of the strips with $30 \mathrm{~mm}$ 
widths, as seen in figure $2 \mathrm{~b}$. After mechanical cutting, the vertical plates of the joint will be milled to reduce the width in the welded area from 30 to $10 \mathrm{~mm}$, as shown in figure 2c. The reducing of the cross-section was done in order to guide both the static traction and the fatigue fracture in the area of the welding seam or its heat affected zone HAZ. It is noticed that the cross section is not reduced sharply from 30 to $20 \mathrm{~mm}$ and milling is done with a radius conection $\mathrm{R}=10 \mathrm{~mm}$, in order not to introduce additional stress concentrators.

The filler material used for the GMAW welding procedure of the welding sampleD is ER 70S-3 in accordance with the specifications of ANSI/AWS A5.18. This filler material 70S-3 is commonly a copper coated carbon steel that contains well balance levels of manganese and silicon which permits the use of $\mathrm{CO} 2$ and alsoArgon -Oxygen shielding gases. Yielding almost a slag free quality weld deposit on most steels it provides an excellent welder satisfaction for post weld clean up. Some typical application includes structural steel, steel buildings, auto frames, sheet metal, ships, barges, railcars, trailers, ornamental iron, furniture storage bins, earthmoving and farm equipment.

The welding parametrs for our application using GMAW procedures with spray arc regime is presented in table 4 . We used for gas protection, $100 \% \mathrm{CO}_{2}$.

Table 4. The welding parameters for GMAW procedures

\begin{tabular}{cccccc}
\hline $\begin{array}{c}\text { Wire } \\
\text { diameter } \\
(\mathbf{m m})\end{array}$ & $\begin{array}{c}\text { Wire } \\
\text { speed } \\
(\mathrm{m} / \mathrm{min})\end{array}$ & Ampers & Volts & $\begin{array}{c}\text { Travel } \\
\text { speed } \\
(\mathrm{m} / \mathrm{min})\end{array}$ & $\begin{array}{c}\text { Flow gas } \\
\text { protection } \\
(\mathbf{l} / \mathbf{m i n})\end{array}$ \\
\hline 1.2 & 4.3 & $235-240$ & $22-23$ & 3.04 & $14-16$ \\
\hline
\end{tabular}

Welding regime parameters used for welding the sample marked with $\mathrm{D}$ are presented in table 4, were Is isthe intensity of the welding current, Ua-is voltage, ts-welding time, Lc-seam length, Vs-welding speed, Vas- wire feed speed and El- the linear energy.

Typical wire chemistry is presented in tables 5 .

Table 5 Typical wire chemistry

\begin{tabular}{ccc}
\hline & $\begin{array}{c}\text { AWS } \\
\text { Specifications }\end{array}$ & $\begin{array}{c}\text { Typical } \\
\text { Wire 70S3 }\end{array}$ \\
\hline $\mathrm{C}(\%)$ & $0.060-0.15$ & 0.10 \\
\hline $\mathrm{Mn}(\%)$ & $0.90-1.40$ & 1.00 \\
\hline $\mathrm{Si}(\%)$ & $0.45-0.75$ & 0.55 \\
\hline P-max $(\%)$ & 0.025 & 0.012 \\
\hline S-max $(\%)$ & 0.035 & 0.012 \\
\hline
\end{tabular}

The weld metal properties are shown in table 6.

For fatigue and tensile tests we used the LVF 100-FM machine, with the following technical features:maximum static load +/- $100 \mathrm{KN}$; maximum dynamic load +/- $100 \mathrm{KN}$; maximum working frequency $50 \mathrm{~Hz}$; piston stroke $100 \mathrm{~mm}$; distance between gripping devices $1200 \mathrm{~mm}$; overall dimensions WxDxH 900x600x2510mm; weight about $830 \mathrm{Kg}$; pump flow 44 l / min / 200 bar. 


\begin{tabular}{ccc}
\hline & $\begin{array}{c}\text { AWS } \\
\text { Specifications }\end{array}$ & $\begin{array}{c}\text { Typical } \\
\text { Wire 70S3 }\end{array}$ \\
\hline Tensile Strength $(\mathrm{MPa})$ & 0.482 & 0.517 \\
\hline Yield Strength $(\mathrm{MPa})$ & 0.399 & 0.430 \\
\hline Elongation - min $(\%)$ & 22 & 30.7 \\
\hline Charpy-V notch at $0{ }^{\circ} \mathrm{C}(\mathrm{J})$ & 27.12 & 81.35 \\
\hline Reduction of area $(\%)$ & $\mathrm{n} / \mathrm{a}$ & 59 \\
\hline Average Brinell Hardness & $\mathrm{n} / \mathrm{a}$ & \\
\hline (Brinell units) & &
\end{tabular}

\section{Results and Discussion}

In figure 3 are shown schematically the cross sections of the specimens, obtained from $\mathrm{D}$ samples, after applying the rehabilitation techniques.

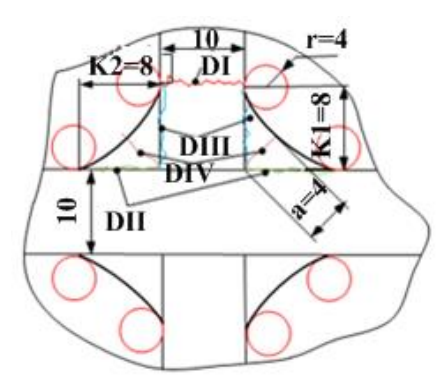

(a)

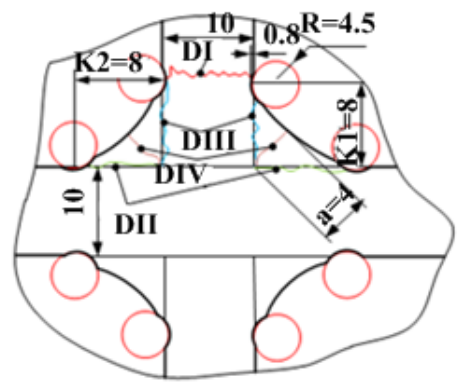

(b)

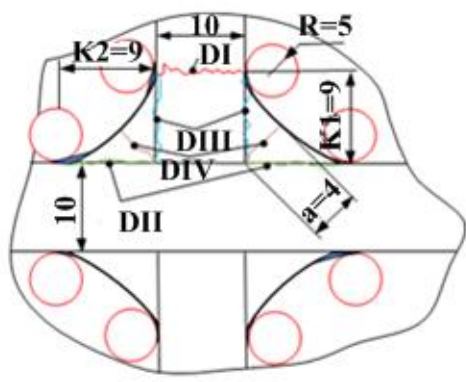

(c)

Figure 3. The cross sections of the specimens:(a) Specimens D1, D2, D3 without rehabilitation; (b) Specimens D4, D5, D6 with "grinding weld toe" rehabilitation technique;(c) Specimens D7, D8, D9 with "WIG remelting weld toe" rehabilitation technique

Geometric elements $\mathrm{K} 1, \mathrm{~K} 2$ and R/r of the welding seams of the specimens from samples $\mathrm{D}$, are shown in table 7,where $a$ is thickness of the welding seam, $K 1$ and $K 2$ are the seam legs and R/r is the radius between seam and base material.

Table 7. Geometric elements of the welding seams for specimens sample D

\begin{tabular}{cccc}
\hline Specimen & $\begin{array}{c}\mathbf{a} \\
(\mathrm{mm})\end{array}$ & $\begin{array}{c}\mathbf{K} \mathbf{1}=\mathbf{K} \mathbf{2} \\
(\mathrm{mm})\end{array}$ & $\begin{array}{c}\mathbf{r} / \mathbf{R} \\
(\mathrm{mm})\end{array}$ \\
\hline D1, D2 and D3 & 4 & 8 & 4 \\
\hline D4, D5 and D6 & 4 & 8 & 4.5 \\
\hline D7, D8 and D9 & 4 & 9 & 5 \\
\hline
\end{tabular}

These geometric elements were determined by measurements made with an specialized software in the macroscopic analysis presented in figure 4 . The macroscopic analysis was performed for each specimen used for static tensile tests as follows: D1 specimen without rehabilitation, D4 specimen on which we apply "grinding weld toe" rehabilitation techniques and the specimen D7 with "WIG remelting weld toe" rehabilitation techniques. Also, the microscopic analysis for the same specimens for the most important areas of the welding such as: base material 
marked with BM, filler material marked with FM and heat affected zone marked with HAZ is presented in figure 5 .

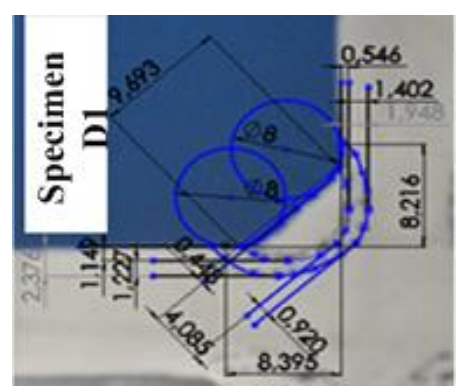

(a)

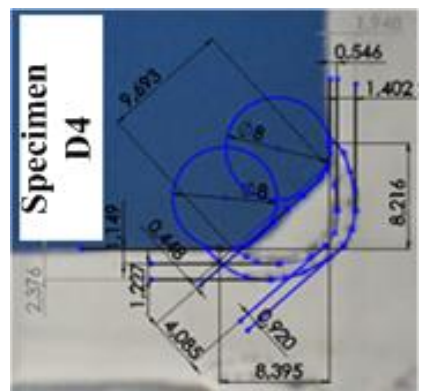

(b)

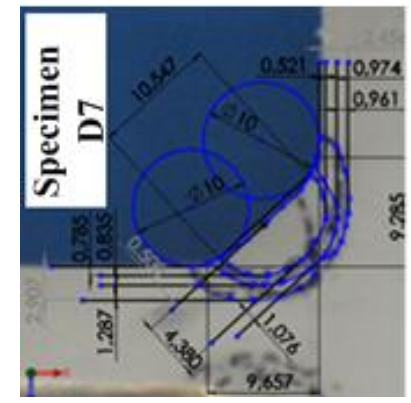

(c)

Figure 4.The macroscopic analysis: (a)For the specimen D1 without rehabilitation; (b)For the specimen D4 with "grinding weld toe"; (c) For the specimen D7 with "WIG remelting weld toe"

The microscopic analysis is made according to EN-1321/200 at 500X magnification factor. The metallographic analysis did not reveal structures outside the equilibrium.

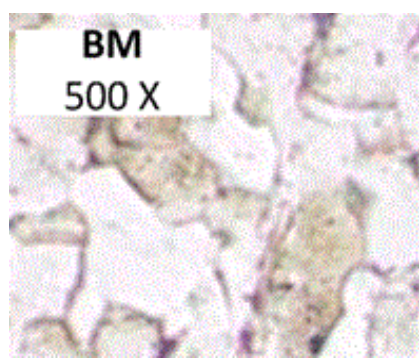

(a)

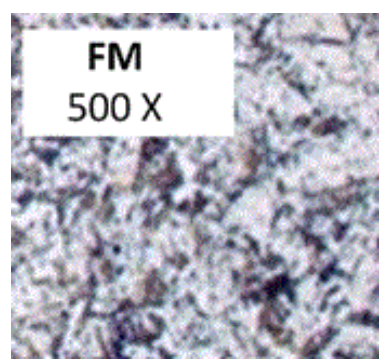

(b)

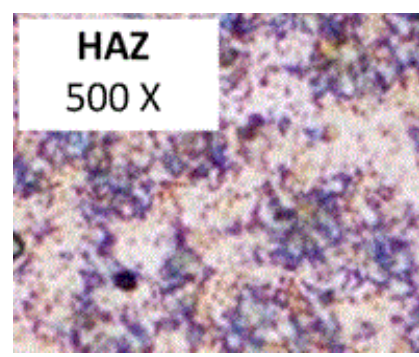

(c)

Figure 5. The microscopic analysis:(a) For the specimen D1 without rehabilitation; (b) For the specimen D4 with "grinding weld toe"; (c) For the specimen D7 with "WIG remelting weld toe"

The measurements for micro-hardnessHV 0,1 are made according to EN 9015-2-2016 along the axes I and II, as we can see from figure 6.

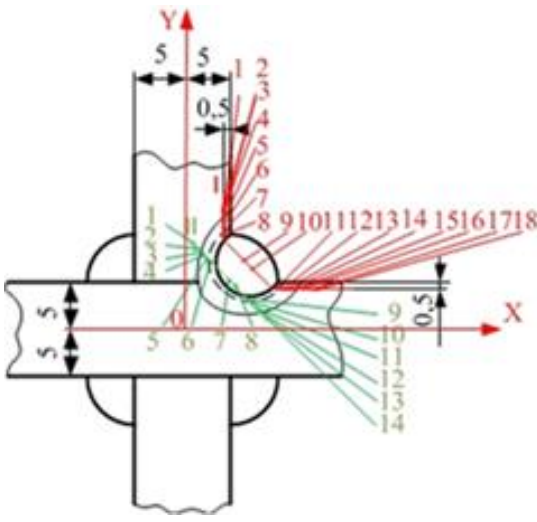

(a)

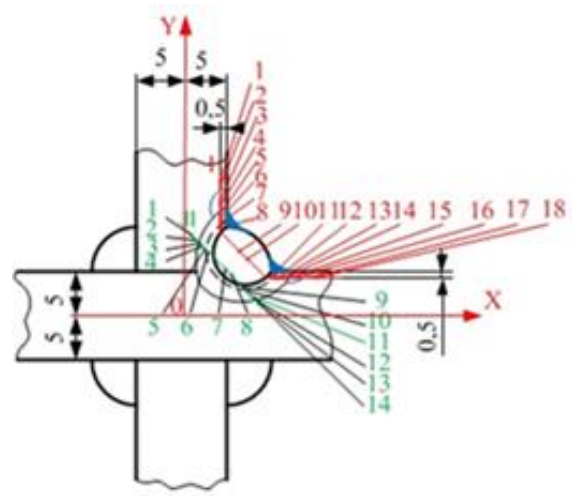

(b)

Figure 6. The measurements for microhardness HV 0.1: (a) For the specimens D1 without rehabilitation and for D4 with "grinding weld toe"; (b) For the specimen D 7 with "WIG remelting weld toe"

The measurements of microhardness are made by the method of finger printing in rows on two perpendicular directions along the plate (horizontal and vertical direction-axis I) and a diagonal 
direction oriented at $120^{\circ}$ to the horizontal sheet plane (axis II ), which should contain the root of the welding seam, as shown in figure 6(a) for specimens D1 and D4and in figure 6(b) for the specimen D7.The variation of microhardness from the axes I and II is shown in figure 7 . We can observe that the lowest value of the microhardness is obtained in the case of the D7 specimen with "WIG remelting weld toe" rehabilitation techniques applied and the highest for the D1 specimen without any rehabilitation techniques applied.

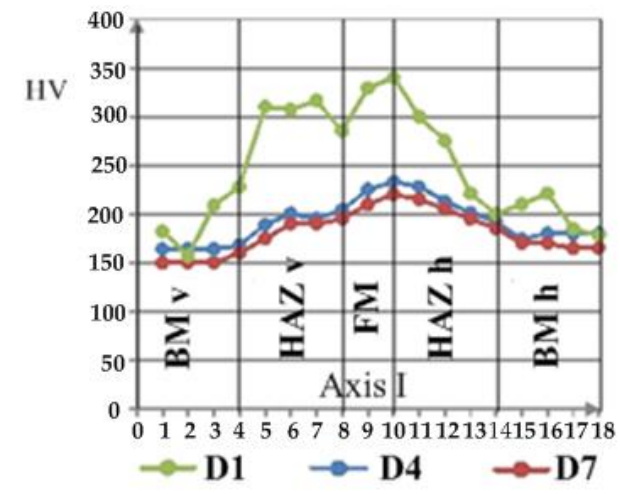

(a)

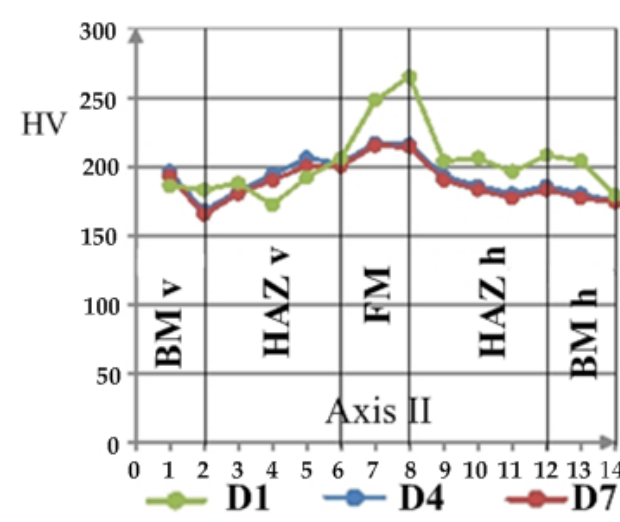

(b)

Figure 7.The variation of microhardness HV 0.1:(a) For the specimens D1, D4 and D7 from axis I; (b) For the specimen s D1, D4 and D 7 from the axis II

Static tensile tests until failure, for D1, D4 and D7 specimens are presented in figure 8. Fatigue test specimens for D samples, one from each set, caught in the test machine's jets, are presented in figure 9 .

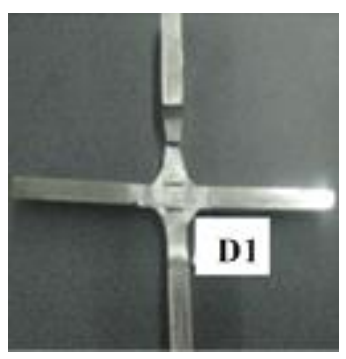

(a)

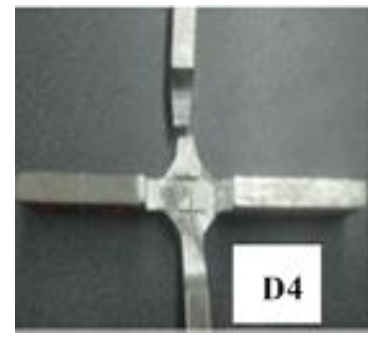

(b)

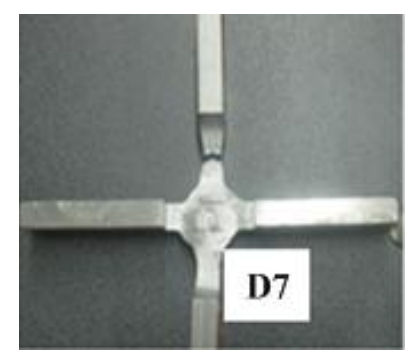

(c)

Figure 8. The static tensile tests: (a) For the specimen D1without rehabilitation; (b) For the specimen D4with "grinding weld toe"; (c) For the specimen D7 with "WIG remelting weld toe"

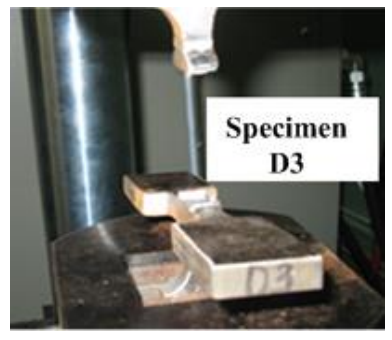

(a)

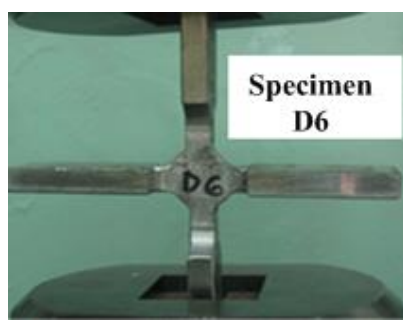

(b)

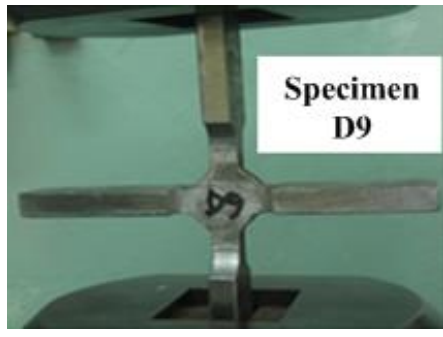

(c)

Figure 9.Fatigue tests: (a) For the specimen D3without rehabilitation; (b) For the specimen D6with "grinding weld toe"; (c) For the specimen D9 with "WIG remelting weld toe" 
The stress strain curves plotted by the machine software for the static tensile tests specimens, are presented in figure 10. We can observe that from specimens made from a HSLA steel, in case of static loads, the rehabilitation technique does not influence the value of the tensile strength.

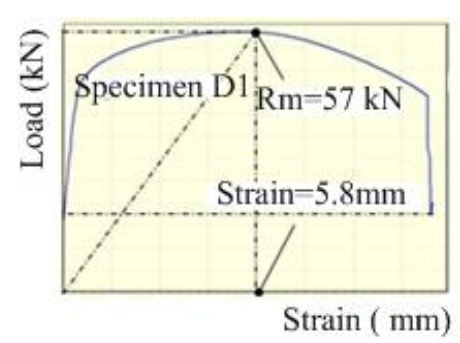

(a)

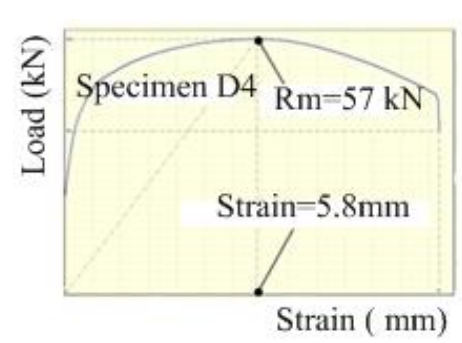

(b)

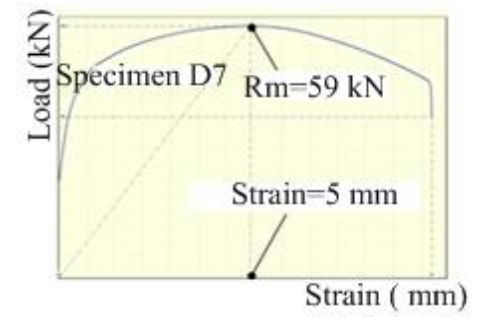

(c)

Figure 10. The stress-strain curves for static tensile tests: (a) For the specimen D1without rehabilitation; (b) For the specimen D4with "grinding weld toe"; (c) For the specimen D7 with "WIG remelting weld toe"

All the fatigue tests were performed at the $10 \mathrm{~Hz}$ frequency, the stress cycle being a symmetrical alternating one, with the asymmetry coefficient $R=-1$, the cycle stress being that of tension compression one. For the three sets of fatigue specimens for D sample, with and without reconditioning techniques applied, three durability curve was drawn and then compared. For tracing the durability curves, two variations of the force were applied to the fatigue test specimens of the sample D ( and the third between them was interpolated ), as follows: for the first set of specimens without rehabilitation we apply to $\mathrm{D} 2 \pm 14 \mathrm{KN}$, to $\mathrm{D} 3 \pm 7.5 \mathrm{KN}$, to the second set of the specimens with "grinding weld toe" rehabilitation techniques we apply for D5 $\pm 14 \mathrm{KN}$, for D6 \pm 7.5 $\mathrm{KN}$ and for third set of test specimens with "WIG remelting weld toe" rehabilitation techniques, we apply to $\mathrm{D} 8 \pm 14 \mathrm{KN}$ and to $\mathrm{D} 9 \pm 7.5 \mathrm{KN}$.Forces applied to the specimens for sample $\mathrm{D}$ and the results obtained from fatigue tests are presented centralized in table 8.

Table 8. Results from fatigue tests for spesimens for sample D

\begin{tabular}{|c|c|c|c|c|c|c|}
\hline No. & $\begin{array}{c}\text { Rehabilitation } \\
\text { technique }\end{array}$ & Mark & $\begin{array}{c}\text { Frequency } \\
(\mathrm{Hz})\end{array}$ & $\begin{array}{c}\text { Force +/-Fi } \\
(\mathrm{kN})\end{array}$ & $\begin{array}{l}\text { Time } \\
\text { (s) }\end{array}$ & $\begin{array}{c}\text { Number of cycles } \\
\text { until failure } \\
\left(\mathrm{N}=\mathrm{t}^{*} \mathrm{f}\right)\end{array}$ \\
\hline 1 & \multirow{2}{*}{$\begin{array}{l}\text { Without } \\
\text { rehabilitation }\end{array}$} & D2 & \multirow{6}{*}{10} & \pm 14 & 1850 & 18500 \\
\hline 2 & & D3 & & $\pm 7,5$ & 22890 & 228900 \\
\hline 3 & \multirow{2}{*}{$\begin{array}{c}\text { Grinding weld } \\
\text { toe }\end{array}$} & D5 & & \pm 14 & 2682 & 26820 \\
\hline 4 & & D6 & & $\pm 7,5$ & 33189 & 331890 \\
\hline 5 & \multirow{2}{*}{$\begin{array}{c}\text { WIG remelting } \\
\text { weld toe }\end{array}$} & D8 & & \pm 14 & 5457 & 54570 \\
\hline 6 & & D9 & & $\pm 7,5$ & 68672 & 686720 \\
\hline
\end{tabular}

The traceability of the durability curves presented in figure 11, is based on the law of variation of the durability curve in linear coordinates, given by the expression (1). 


$$
\Delta \sigma(n)=\sqrt[p]{\frac{10^{r}}{n}}
$$

In the expression (1)where $\Delta \sigma$ is stress variation, $1 / \mathrm{p}$ is the slope of the curve, $\mathrm{r}=\lg \mathrm{A}$ is the intersection between the curve and vertical axis and $n$ is number of cycles.

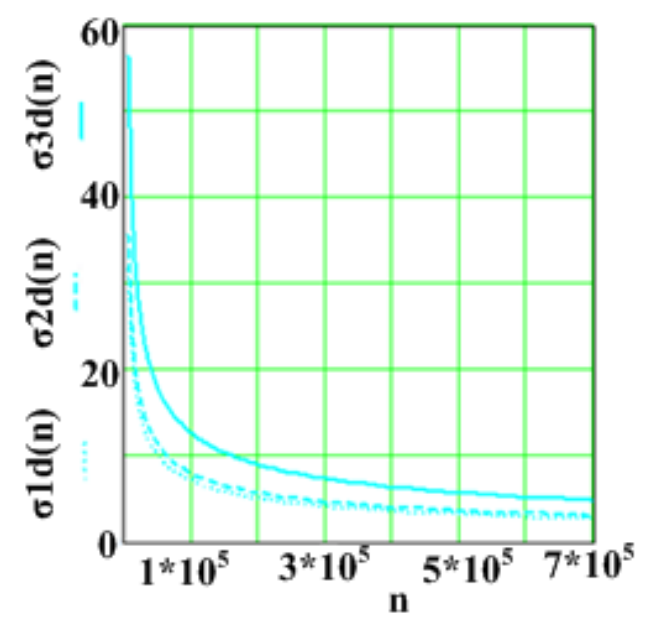

Figure 11. The durability curves: n-number of cycles, $\sigma 1 d(n), \sigma 2 d(n), \sigma 3 d(n)$-the mathematical functions of the durability curves

For the sample D, using the Math-CAD calculation program, for specimen D2, D3, with no rehabilitation technique, we found the values $p=2$ and $r=6.7$, for which the graph of the function $\sigma 1 \mathrm{~d}(\mathrm{n})$ approaches most of our points $\mathrm{d} 1=(18500 ; 46128 ; 228904)$ and of witch represents the force vector $\mathrm{f}=(14 ; 9 ; 6)$. The shape of this curve is shown in figure 11 , with green dot line. For the second set of specimens D5, D6 with "weld toe grinding", also with the help of MathCAD, the values $p=2$ and $r=6.8$ were found for which the graph of the function $\sigma 2 d(n)$ is closer to our points our $d 2=(26820 ; 179358 ; 331896)$ and the force vector is $f=(14 ; 9 ; 6)$. The shape of this curve is also shown in figure 11, with the broken green line. For the third set of specimens D8, D9 with "WIG remelting weld toe", also using the MathCAD program, found the values $\mathrm{p}=2$ and $\mathrm{r}=7.2$ for which the graph of the function $63 \mathrm{~d}(\mathrm{n})$ approaches the one of the our points $\mathrm{d} 3=(54570$; $370645 ; 686720)$ and the force vector is $f=(14 ; 9 ; 6)$. The shape of this curve is also shown in figure 11 with the green line continues.

We can see from table 8 and figure 11 that in case of welded structure made from a HSLA steel, that the longest fatigue life time is achieved with the "WIG remelting weld toe" technique and the smallest if no rehabilitation technique is applied. The explanation is that by applying the rehabilitation techniques the stress concentrators are removed from the intersection between the base and the filler material, obtaining a smooth connection between them. The biggest smooth conection and the longest fatigue life time is achieved with applying the "WIG remelting weld toe" technique.

\section{Conclusions}

The main conclusions are submarised below:

- As we can observe from figure 10 regardless of whether rehabilitation techniques are applied or not, on the specimens D1, D4 and D7, all fractures in case of static loads have occurred at a close range, between 57 to $59 \mathrm{kN}$. This shows that it is not justified to 
apply rehabilitation techniques to the welded structure statically stressed made from a HSLA steel.

- As can be seen in figure 11, for the three sets of specimens from sample D as follows: D2 and D3 without rehabilitation ( green dot line curve ), D5 and D6 with "weld toe grinding" rehabilitation technique ( broken green line ) and D8 and D9 with "WIG remelting weld toe" rehabilitation technique (green line continues), the durability curves are not asymptotic to the horizontal axis and this means that practically in case of the fatigue stressed welding structures made from HSLA steel,we cannot talk about the infinite fatigue resistance $\sigma_{0}$ according to the classical Wohler curve, in our case having a limited fatigue life time. This demonstrate that in case of fatigue stressed welded structures, it is justified to apply the rehabilitation techniques in order to increase the fatigue lifetime.

- Also from figure 11 it is observed that for a certain value of stress variation $\Delta \sigma$, the specimens D8 and D9 with "WIG remelting weld toe" resist the most number of fatigue cycles, the specimens without rehabilitation, D2 and D3 resist the smallest number of fatigue cycles and the intermediate place is occupied by the specimens D5 and D6 with "weld toe grinding".

- Based on the results from table 8, we can conclude that we have an increase of approximately $40 \%$ in the number of cycles up to fatigue failure in case of "grinding weld toe" specimens, respectively with $195 \%$ in case of "WIG remelting weld toe" specimens compared with the specimens without rehabilitation.

- The metallographic analysis for all specimens analyzed, did not reveal structures outside the equilibrium, as we can observe from figure 5.

- As we can observe from figure 7, from the variation of microhardness from the axes I and II, of all analyzed specimens, after the application of the rehabilitation techniques, no fragile structures are obtained in which the dangerous value of 350 Vickers units is exceeded.

- The general conclusion is that in the case of HSLA welded structures fatigue stressed, it is justified to apply those two rehabilitation techniques "grinding weld toe" and "WIG remelting weld toe", that have a beneficial influence in the case of variable loads in the sense that they lead to increase the fatigue life, but their application is not justified in the case of statically loaded structures, to which these rehabilitation techniques do not bring any significant benefit.

Author Contributions: ClaudiuBabis and Gheorghe Solomon, performed the experiments, analyzed the data and wrote the initial draft of the manuscript.Oana Chivu and Gabriel Iacobescu contributed to design the experiments, data interpretation and revising the manuscript. Anca Alexandra Purcarea, supervised the project and provided valuable suggestions.Conflicts of Interest:The authors declare no conflict of interest.

\section{References}

1. Chuang Cui, Qinghua Zhang, Yi Bao, Jiping Kang, Yizhi Bu. Fatigue performance and evaluation of welded joints in steel truss bridges, Journal of Constructional Steel Research2018, 148, 450-456 [Google Scholar] 
2. Bin Cheng, Xinghan Ye, Xinger Cao, Dibu Dave Mbako, Yishan Cao. Experimental study on fatigue failure of rib-to-deck welded connections in orthotropic steel bridge decks, International Journal of Fatigue 2017, 103, 157-167 [Google Scholar]

3. John Leander. Reliability evaluation of the Eurocode model for fatigue assessment of steel bridges, Journal of Constructional Steel Research, 2018, 141, 1-8 [Google Scholar] [CrossRef]

4. FilippoBerto. Fatigue Damage, Metals, 2017, 7, 394 [Google Scholar] [CrossRef]

5. Hao Yuan, Wei Zhang, Gustavo M. Castelluccio, Jeongho Kim, Yongming Liu. Microstructure-sensitive estimation of small fatigue crack growth in bridge steel welds, International Journal of Fatigue2018, 112, 183-197 [Google Scholar] E. Bayraktar, H. Xue, F. Ayari, C. Bathias. Torsional fatigue damage mechanisms in the very high cycle regime, Journal of Archives of Materials Science and Engineering, 2010, 43, 77-86

6. D.L.Chen, B.Weiss, R.Stickler and Z.G.Wang, Re-considerations of fatigue crack closure effect, Chinese Journal of Materials Research, 1995, 9, 162-179. [Google Scholar] [CrossRef]

7. D.L.Chen, M.C.Chaturvedi, N.Goel and N.L.Richards, Fatigue crack propagation behavior of X2095 Al-Li alloy, International Journal of Fatigue, 1999, 21, 1079-1086. [Google Scholar] [CrossRef]

8. Hsin Jen Hoh, John Hock Lye Pang, Kin Shun Tsang. Stress intensity factors for fatigue analysis of weld toe cracks in a girth-welded pipe, International Journal of Fatigue, 2016, 87, 279-287 [Google Scholar]

9. TadeuszŁagoda, PawełBiłous, ŁukaszBlacha. Investigation on the effect of geometric and structural notch on the fatigue notch factor in steel welded joints, International Journal of Fatigue, 2017, 101, 224-231 [Google Scholar]

10. Zhi-Gang Xiao, Tao Chen, Xiao-Ling Zhao. Fatigue strength evaluation of transverse fillet welded joints subjected to bending loads, International Journal of Fatigue, 2012, 38, 57-64 [Google Scholar] [CrossRef]

11. Xing Wei, Lin Xiao, Shiling Pei. Fatigue assessment and stress analysis of cope-hole details in welded joints of steel truss bridge, International Journal of Fatigue, 2017, 100, 136-147 [Google Scholar]

12. Tsuyoshi Shiozaki, Naoki Yamaguchi, YoshikiyoTamai, JiroHiramoto, Kazuhiro Ogawa. Effect of weld toe geometry on fatigue life of lap fillet welded ultra-high strength steel joints, International Journal of Fatigue, 2018, 116, 409-420 [Google Scholar] [CrossRef]

13. Wolfgang Fricke, LuyaoGao, Hans Paetzold. Fatigue assessment of local stresses at fillet welds around plate corners, International Journal of Fatigue, 2017, 101, 169-176 [Google Scholar] [CrossRef]

14. Liang Zong, Gang Shi, Yuan-Qing Wang, Jia-Bao Yan, Yang Ding. Investigation on fatigue behaviour of load-carrying fillet welded joints based on mix-mode crack propagation analysis, Archives of Civil and Mechanical Engineering, 2017, 17, 677-686 [Google Scholar] [CrossRef]

15. EbrahimHarati, Leif Karlsson, Lars-Erik Svensson, KamelliaDalaei. The relative effects of residual stresses and weld toe geometry on fatigue life of weldments, International Journal of Fatigue, 2015, 77, 160-165 [Google Scholar]

16. D. TchoffoNgoula, H. Th. Beier, M. Vormwald. Fatigue crack growth in cruciform welded joints: Influence of residual stresses and of the weld toe geometry, International Journal of Fatigue, 2017, 101, 253-262 [Google Scholar]

17. Armando, L.,Rama, I., José ,A.M.Ferreir, Carlos A., G.M.BrancoC. Fatigue behaviour of T welded joints rehabilitated by tungsten inert gas and plasma dressing, Materials $\mathcal{E}$ Design, 2011, 32 (11), 4705-4713 [Google Scholar] [CrossRef]

18. Bayraktar E., Kaplan D., Schmidt F., Paqueton H., Grumbach M.. State of art of impact tensile test (ITT): Its historical development as a simulated crash test of industrial materials and presentation of new "ductile/brittle" transition diagrams, Journal of Materials Processing Technology, 2008, 204, 313-326 [Google Scholar] [CrossRef]

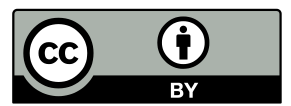

(C) 2018 by the authors. Submitted for possible open access publication under the terms and conditions of the Creative Commons Attribution (CC BY) license (http://creativecommons.org/licenses/by/4.0/). 